\title{
EFFECTIVENESS OF PRELOADING IN PREVENTION OF SPINAL INDUCED HYPOTENSION DURING LSCS
}

Shridhar N. Ekbote' ${ }^{1}$ A. Srinivasa Murthy²

\section{HOW TO CITE THIS ARTICLE:}

Shridhar N. Ekbote, A. Srinivasa Murthy. "Effectiveness of Preloading in prevention of Spinal Induced Hypotension during LSCS". Journal of Evolution of Medical and Dental Sciences 2014; Vol. 3, Issue 06,

February 10; Page: 1420-1425, DOI: 10.14260/jemds/2014/2001

ABSTRACT: BACKGROUND: The hypotension induced by spinal anesthesia in caesarean section patients can have deleterious effects on both mother and fetus. This can be prevented or minimized by various methods like trendelenburg position, left uterine displacement, prophylactic vasoconstrictor, volume preloading etc. Volume preloading is commonly practiced method. However, few recent studies have found lack of benefit by fluid preload. Hence this study. AIM: To assess efficacy of fluid preloading using RL in preventing spinal induced hypotension in caesarean section patients. METHODOLOGY: Two groups' control (C) group and study (S) group comprising of 30 parturients each, belonging to ASA I and ASA II coming for elective caesarean section under spinal anesthesia were selected. Parturients in control group received no fluid preload whereas those in study group were preloaded with 1L RL. After spinal anesthesia, patients' blood pressure and other vital parameters were monitored intraoperatively every $2 \mathrm{~min}$ for first $20 \mathrm{~min}$ and then every $5 \mathrm{~min}$ till the end of surgery. RESULTS AND CONCLUSION: Parturients who received RL preloading had lesser number of hypotensive episodes and lesser severe degree of hypotension than those without volume preload. Volume preloading has its own beneficial effects on incidence of spinal induced hypotension in parturients undergoing elective LSCS.

KEYWORDS: Caesarean section, spinal anesthesia, hypotension, fluid preloading.

INTRODUCTION: For many reasons, delivery of baby by caesarean route has become increasingly common. Spinal anesthesia appears to be the preferred technique of anaesthesia ${ }^{1}$. Although spinal anesthesia appears to be safe, it can produce several immediate and serious complications. Severe hypotension is one of them which can endanger the life of both mother and the foetus ${ }^{2}$. Several measures have been advocated to decrease the severity of spinal induced hypotension like use of prophylactic vasoconstrictor, leg compression, trendelenberg position, left sided uterine displacement, but fluid preloading is commonly practiced ${ }^{3-7}$. Many studies have demonstrated its effectiveness ${ }^{7,8}$ but few recent studies have found lack of its benefit in caesarean section patients ${ }^{9,10}$. Hence we have undertaken this study to reassess the efficacy of fluid preloading in parturients using Ringer's lactate solution.

MATERIALS AND METHODS: After obtaining approval from ethics committee and informed written consent from patients, two groups, study group and control group, comprising of 30 parturients each were selected. Pregnant patients between the age group of 18years to 40 years, similar in demographic characteristics, belonging to ASA I and ASA II, coming for elective caesarean section were chosen for the study.

After overnight fasting, all the parturients were premedicated with inj. Rantac 50mg i.v. 1 hour before surgery. Patients basal vital parameters were recorded preoperatively using 
multiparameter monitor in the 0.T. After securing I.V access using 18G cannula, preloading of Study group patients were started using 1 liter of ringer's lactate solution over a period of 15-20 min before spinal anesthesia whereas Patients in control group remained unpreloaded. Spinal block was instituted with 25G quincke's spinal needle at the level of L3-L4 or L4-L5 using 2 to $2.2 \mathrm{ml}$ of Bupivacaine $0.5 \%$ heavy. Patients were positioned supine with lateral tilt. After obtaining adequate level of block, surgery was performed. All the parturients were given $\mathrm{O}_{2}$ by facemask at $5 \mathrm{~L} / \mathrm{min}$. Any hypotensive episodes were treated using $5 \mathrm{mg}$ Ephedrine I.V and additional infusion of i $\mathrm{v}$ fluids. Following observations were made,

Heart rate and blood pressure were recorded every $2 \mathrm{~min}$ for the first $20 \mathrm{~min}$ then every 5 min. ECG and $\mathrm{SpO}_{2}$ were monitored continuously till the end of surgery. In addition, height of the block, amount of i v fluids used, amount of Ephedrine needed, episodes of nausea or vomiting and any allergic reactions to i v fluids were noted. We have considered fall in systolic blood pressure to $<20$ $\%$ of the basal value as hypotension. Data collected were subjected to statistical analysis using statistical softwares namely SPSS, MedCalc etc to get the information on incidence of hypotension, bradycardia, requirement of vasopressor, allergic reactions and cardiovascular collapse if any.

\section{RESULTS:}

Demographic characteristics: Age, height, and weight of both the groups were comparable as shown in Table No. 1.

\begin{tabular}{|c|c|c|}
\hline BASIC CHARECTERISTICS & CONTROL GROUP & STUDY GROUP \\
\hline AGE in years & $24.63 \pm 3.98$ & $24.10 \pm 4.35$ \\
\hline WEIGHT in kgs & $63.83 \pm 3.71$ & $64.47 \pm 3.71$ \\
\hline HEIGHT in cms & $157.09 \pm 3.37$ & $157.95 \pm 3.67$ \\
\hline TABLE NO. 1: Comparison of demographic characteristics between the 2 groups
\end{tabular}

The age of parturients ranged between 17 and 36 years. The mean age in control group was 24.63years with SD 3.98 and that in study group was 24.10 years with SD 4.35. The mean weights in control and study group were $63.83 \mathrm{kgs}$ (SD 3.71) and 64.47 (SD 3.71) kgs respectively. The height of the parturients ranged between $152 \mathrm{cms}-165 \mathrm{cms}$. The mean height in control group and study group were respectively $157.09 \mathrm{cms}$ (SD 3.37) and $157.95 \mathrm{cms}$ (SD 3.67). Hence, age, height and weight were comparable in both the groups and were found to be statistically insignificant.

INCIDENCE OF HYPOTENTION:- The incidence of hypotension in control group and study group were $80 \%$ and $57 \%$ respectively and were found to be statistically significant with $\mathrm{p}=0.02$.

\begin{tabular}{|c|c|c|c|}
\hline INCIDENCE OF HYPOTENSION & CONTROL GROUP & STUDY GROUP & TOTAL \\
\hline ABSENT & 6 & 13 & 19 \\
\hline PRESENT & 24 & 17 & 41 \\
\hline Total & 30 & 30 & 60 \\
\hline
\end{tabular}


(Chi squared equals 3.774 with 1 degree of freedom. The one-tailed $\mathrm{P}$ value equals 0.0260 . The association between groups and outcomes is considered to be statistically significant.) EPHEDRINE REQUIREMENT: The Ephedrine use in control group is more as seen from the following table no. 3 .

\begin{tabular}{|c|c|c|}
\hline REQUIREMENT OF EPHEDRINE & CONTROL GROUP (n=30) & STUDY GROUP (n=30) \\
\hline Not Required & $6(20 \%)$ & $13(43 \%)$ \\
\hline Required & $24(80 \%)$ & $17(57 \%)$ \\
\hline $5 \mathrm{mg}$ & $13(43 \%)$ & $9(30 \%)$ \\
\hline $10 \mathrm{mg}$ & $06(20 \%)$ & $8(27 \%)$ \\
\hline 15mg & $05(16 \%)$ & - \\
\hline \multicolumn{2}{|c|}{ TABLE NO. 3: The Ephedrine use in control group }
\end{tabular}

DISCUSSION: Hypotension following spinal anesthesia for Caesarean Section is the commonest serious problem with an incidence reported in the literature of upto 85\%. This is in spite of pregnant patients having $40-50 \%$ of more blood volume at term compared to non-pregnant patients. Pregnant patients at term are more prone for hypotension due to aortocaval compression by fetal head and higher level of sympathetic blockade owing to increased spread of local anesthetic in CSF. Hypotension, hazardous to the mother and to the fetus is better prevented than treated. Vasodilatation due to spinal sympathetic blockade causes decreased venous return to heart and decreases cardiac output. This decreased cardiac output in turn decreases uteroplacental perfusion and affects APGAR score. Therefore efforts were made to increase cardiac preload before spinal anesthesia in the hope of preventing subsequent hypotension; the concept of intravenous 'preload' was born. Different investigators have used variety of fluids like crystalloids, colloids, albumin for preloading and reported regarding their beneficial effect on the incidence of spinal induced hypotension in parturients.

Greiss and Crandell6, in 1965, were the first to show that rapid infusion of $500 \mathrm{ml}$ of i. v fluid had partly restored the uterine blood flow in parturient rendered hypotensive by spinal anesthesia.

In 1968, Wollman and Marx ${ }^{7}$ demonstrated that rapid infusion of $1000 \mathrm{ml}$ of $5 \%$ Dextrose in Lactated ringer's solution is safe and effective method of reducing the incidence of hypotension in parturients.

But, in 1976, Clark et $\mathrm{al}^{8}$, after observing hypotension as persistent problem, studied the combined effect of left uterine displacement and volume preloading on the incidence of hypotension and reported that fluid preloading alone or combination of fluid preloading and left uterine displacement is an effective means of controlling hypotension in parturients.

Similarly, Mathru et al ${ }^{11}$ in 1980, in their study showed that infusion of 5\% albumin in D5RL in combination with left uterine displacement is an effective method of acute hydration for prevention of hypotension during Caesarean section performed under spinal anesthesia.

In 1982, in a study, Hallworth et al ${ }^{12}$, found that use of $500 \mathrm{ml}$ each of Polygelatin and Hartmann's solution as preloading fluid is superior to use of $1000 \mathrm{ml}$ of Hartmann's solution alone.

Karinen et $a^{13}$ (1995), when they compared hemodynamic effects of $1 \mathrm{~L}$ of RL with that of $500 \mathrm{ml}$ of colloid, they found that the incidence of hypotension was more in the crystalloid group than in the colloid group. 
Sharma et $\mathrm{al}^{14}$ (1997) also compared the effect of $1 \mathrm{~L}$ of RL preload with that of $500 \mathrm{ml}$ of Hetastarch, on the incidence of hypotension following spinal anesthesia for Caesarean section and similarly, their study also found that colloids are better controller of hypotension than crystalloids.

But the use of colloid as preloading fluid is associated with risk of life threatening allergic responses and also colloids are expensive and are not available easily. Moreover, in a study conducted by Ramanathan et al 15 in 1983, to assess whether infusion of normal serum albumin (NSA) offers any advantages over Ringer's acetate solution, it was found that both crystalloid and colloid prehydration produced equally satisfactory maternal and fetal outcomes.

Because of the persistence of hypotension in spite of preloading, few investigators have advocated use of higher volumes of preloading, perhaps in the belief that enough preload had not been used in earlier studies. This was evident in a study by Ueyama $\mathrm{H}^{16}$ et al who showed that the augmentation of blood volume with preloading, regardless of fluid used, must be large enough to result in a significant increase in cardiac output for effective prevention of hypotension.

Study conducted by Lewis et $\mathrm{al}^{17}$ also corroborate that the incidence of hypotension could be substantially reduced by increasing crystalloid prehydration to $2000 \mathrm{ml}$.

However, in a study conducted by Park GE18 et al in 1996, to assess the effect of varying volumes of crystalloid administration before Caesarean delivery on maternal hemodynamics, it was found that increasing the volume of crystalloid administered to $30 \mathrm{ml} / \mathrm{kg}$ has no significant effect on maternal hemodynamics or ephedrine requirement after spinal anesthesia and has no apparent benefit. Moreover, unbridled use of large volumes of crystalloid fluid risks acute hemodilution with decreased oxygen carrying capacity, and pulmonary edema.

Other than preloading, this problem can also be tackled by use of TED stockings; wrappings of legs, use of vasopressors etc. but none of these techniques are completely effective in preventing hypotension. Moreover these techniques are either less effective than preloading or carry severe adverse effects.

In our study, 24 patients in control group and only 17 patients in study group developed hypotension. The difference was statistically significant with $\mathrm{p}$ value $<0.05$. During the study, hypotension was initially treated with head low tilt and additional use of i.v. Fluids. Later on vasopressor (Ephedrine in 5mg boluses) was used if hypotension persisted.

The amount of vasopressor required to treat hypotension was found to be $23 \%$ more in control group compared to study group.

Because the factors like amount of intraoperative blood loss, amount of oxytocin used also influence the incidence of hypotension, they were also studied and were found to be comparable in both the groups. Other parameters like age of the patient, height of the patient, weight of the patient, dosage of local anesthetic used for spinal block and level of sensory block obtained were intentionally kept comparable to avoid these factors influencing our study. Incidences of nausea, vomiting and shivering were comparable in both the groups. 6 patients in control group and 3 patients in study group had vomiting and were treated using Ondansetron.

The lack of benefit by fluid preload has prompted some authors to abandon routine preloading. For instance, Jackson et al ${ }^{19}$ in 1995 compared the hemodynamic effects of $1000 \mathrm{ml}$ preload with $200 \mathrm{ml}$ preload of crystalloid solution administered $10 \mathrm{~min}$ before spinal anesthesia for Caesarean delivery and found no difference in ephedrine requirement between the two groups. 
Similarly, Husaini et $\mathrm{al}^{20}$ (1998) in a study found that the group that received $1 \mathrm{~L}$ RL preloading had similar incidence of hypotension as that of control group, which received no preload. However, we feel that the results of our study suggest that there may still be a place for volume preloading and further investigations using colloids are warranted before we abandon practice of preloading in favor of aggressive use of vasoconstrictors.

CONCLUSION: - It can be concluded that prevention of hypotension to avoid its deleterious effects on both the mother and fetus can be attempted using simpler and more safer methods like preloading using RL than use of albumin, colloids or vasopressors which carry inherent risk of anaphylaxis and other life threatening adverse effects.

\section{REFERENCES:}

1. Schneider SM, Levinson G. Anesthesia for Caesarean Section, chapter 12, Anesthesia for Obstetrics, $3^{\text {rd }}$ ed, Williams and Wilkins 1993:pp 211-239.

2. Rout CC, Rocke DA. Prevention of hypotension following spinal anesthesia for caesarean section. Int Anaesthesiol Clin 1994; 32:117-132

3. Kang YG, Abouleish E, Caritis S. Prophylactic intravenous Ephedrine infusion during spinal anesthesia for Caesarean Section. Anaesth Analg 1982; 61: 839-842

4. Jorgensen J, Christensen PK, Sonnenschein CH. Compression stockings as prevention of hypotension in Caesarean Section during spinal anesthesia. Ugeskr-Laeger 1996;158:15261529.

5. Bhagwanjee S, Rocke DA, Rout CC, Koovarjee RV, Brijball R. Prevention of hypotension following spinal anesthesia for elective Caesarean Section by wrapping of legs. Br J Anaesth 1990;65:819822

6. Greene NM, Brull SJ. Physiology of spinal anesthesia $4^{\text {th }}$ ed, Williams and Wilkins 1993 pp 163.

7. Wollman SB, Marx GF. Acute hydration for prevention of hypotension of spinal anesthesia in parturients. Anesthesiology 1968;29:374-380.

8. Clark RB, Thompson DS, Thompson CH. Prevention of spinal hypotension associated with Caesarean Section. Anaesthesiology 1976;45:670-674.

9. Rout CC, Rocke DA, Lewin L, Gouse E, Reddy D. A reevaluation of role of crystalloid preloading in the prevention of hypotension associated with spinal anesthesia for elective caesarean section. Anaesthesiology 1993;79:262-269.

10. Rocke DA, Rout CC. Volume preloading, spinal hypotension and Caesarean section (Editorial Ī) Br J Anaesth 1995;75:257-259.

11. Mathru M, Rao TLK, Kartha RK, Shanmugham M, Jackobs HK. Intravenous albumin administration for prevention of spinal hypotension during Caesarean section. Anaes Analg 1980;59:655-658.

12. Hallworth D, Jellicoe JA, Wilkes RG. Hypotension during epidural anesthesia for caesarean section: A comparison of crystalloid and colloid solutions. Anaesthesia 1982;37:53-56.

13. Karinen J, Rasanen J, Alahuhta S, Joupilla R, Joupilla P. Effects of crystalloid and colloid preloading on uteroplacental and maternal hemodynamic state during spinal anesthesia for caesarean section. Br J Anaesth 1995;75:531-535. 
14. Sharma SK, Gajraj NM, Sidawi JE. Prevention of hypotension during spinal anesthesia: A comparison of intravascular administration of hetastarch versus lactated Ringer's solution. Anaesth Analg 1997; 84: 111-114.

15. Ramanathan S, Masih A, Rock I, Chalon J, Turndorf H. Maternal and fetal effects of prophylactic hydration with crystalloids or colloids before epidural anesthesia. Anaesth Analg 1983;62:673678.

16. Ueyama H, He YL, Tanigami H, Mashimo T, Yoshia I. Effects of crystalloid and colloid preload on blood volume in the parturient undergoing spinal anesthesia for elective Caesarean section. Anaesthesiology 1999;91:1571-1576.

17. Lewis M, Thomas P, Wilkes RG. Hypotension during epidural anesthesia for Caesarean section. Anaesthesia 1983;38:250-253.

18. Park GE, Hauch MA, Curlin F, Datta S, Bader AM. The effects of varying volumes of crystalloid administered before Caesarean delivery on maternal hemodynamics and colloid osmotic pressure. Anaesth Analg 1996;83:299-303.

19. Jackson R, Reid JA, Thornburn J. Volume preloading is not essential to prevent spinal induced hypotension at caesarean section. Br J Anaesth 1995;75:262-265.

20. Husaini SW, Russell IF. Volume preloading: Lack of effect in prevention of spinal-induced hypotension at caesarean section. Inter J Obstet Anaesth 1998;7:76-81.

\section{AUTHORS:}

1. Shridhar N. Ekbote

2. A. Srinivasa Murthy

\section{PARTICULARS OF CONTRIBUTORS:}

1. Assistant Professor, Department of Anaesthesiology, Raichur Institute of Medical Sciences, Raichur.

2. Professor, Department of Anaesthesiology, Raichur Institute of Medical Sciences, Raichur.

\section{NAME ADDRESS EMAIL ID OF THE} CORRESPONDING AUTHOR:

Dr. Shridhar N. Ekbote, \#G3, Malhar Building, H. No. 1-12-32/32, Daddy Colony, Raichur - 584102, Karnataka.

E-mail: sridhar.ekbote9@gmail.com

Date of Submission: 06/12/2013. Date of Peer Review: 07/12/2013. Date of Acceptance: 28/01/2014. Date of Publishing: 05/02/2014. 